\title{
Activation, homing, and role of the mesenchymal stem cells in the inflammatory environment
}

This article was published in the following Dove Press journal:

Journal of Inflammation Research

15 December 2016

Number of times this article has been viewed

\section{Lukáš Zachar \\ Darina Bačenková \\ Ján Rosocha}

Associated Tissue Bank of Faculty of Medicine of P. J. Šafárik University and University Hospital of L. Pasteur, Košice, Slovak Republic
Correspondence: Lukáš Zachar Associated Tissue Bank of Faculty of Medicine of P. J. Šafárik University and University Hospital of L. Pasteur, Trieda SNP I, Košice 040 I I, Slovak Republic Email lukas.zachar@upjs.sk

\begin{abstract}
Human mesenchymal stem cells (MSCs) are considered to be a promising source of cells in regenerative medicine. They have large potential to differentiate into various tissuespecific populations and may be isolated from diverse tissues in desired quantities. As cells of potential autologous origin, they allow recipients to avoid the alloantigen responses. They also have the ability to create immunomodulatory microenvironment, and thus help to minimize organ damage caused by the inflammation and cells activated by the immune system. Our knowledge about the reparative, regenerative, and immunomodulatory properties of MSCs is advancing. At present, there is a very comprehensible idea on how MSCs affect the immune system, particularly in relation to the tissue and organ damage on immunological basis. Hitherto a number of effective mechanisms have been described by which MSCs influence the immune responses. These mechanisms include a secretion of soluble bioactive agents, an induction of regulatory $\mathrm{T}$ cells, modulation of tolerogenic dendritic cells, as well as induction of anergy and apoptosis. MSCs are thus able to influence both innate and adaptive immune responses. Soluble factors that are released into local microenvironment with their subsequent paracrine effects are keys to the activation. As a result, activated MSCs contribute to the restoration of damaged tissues or organs through various mechanisms facilitating reparative and regenerative processes as well as through immunomodulation itself and differentiation into the cells of the target tissue.
\end{abstract}

Keywords: stem cells, migration, bioactive factors, immunomodulatory microenvironment, regulatory $\mathrm{T}$ cells, tissue regeneration

\section{Introduction}

Mesenchymal stem cells (MSCs) were originally described as an adherent population of fibroblast-like cells located in the bone marrow which are capable of osteogenic differentiation. ${ }^{1}$ Subsequently, it was shown that these multipotent cells can be found in all tissues that are capable of regeneration and are located typically in the perivascular niches as pericytes expressing CD146. ${ }^{2}$ However, not all MSCs can be considered equivalent to pericytes, nor all pericytes have characteristic MSCs properties. ${ }^{3}$

Nowadays, MSCs are routinely isolated from tissues such as adipose tissue, peripheral blood, umbilical cord, placental membranes, and many others. ${ }^{4-7}$ These cells have a remarkable ability to proliferate in vitro; hence, it is possible to harvest quickly the required number of cells either for experimental use or for targeted cell therapies. MSCs play a key role in homeostasis maintenance and maturation of hematopoietic cells in the bone marrow. ${ }^{8}$ 
MSCs were initially characterized according to their clonogenic potential represented by the ability to create colony-forming units-fibroblasts (CFU-F). The frequency of CFU-F in the bone marrow is around one cell in $10^{4}-10^{5}$ mononuclear cells. ${ }^{9}$ The MSCs are characterized by the expression of various surface antigens, ${ }^{10}$ but none of them seem to be expressed exclusively by MSCs. Therefore, the International Society for Cell Therapy issued guidelines by which MSCs are defined on the basis of the following three

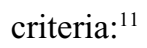

1. MSCs have to be adherent to the culture on plastic under standard tissue culture conditions.

2. MSCs must express surface markers such as CD44, CD71, CD73, CD90, and CD105 but lack the expressions of CD11b, CD14, CD19, CD34, CD45, CD79 $\alpha$, and costimulatory molecules CD80 and CD86. They also have to exhibit low expression levels of major histocompatibility complex (MHC) class I.

3. MSCs must have the ability to differentiate in vitro into osteoblasts, chondrocytes, and adipocytes.

These main characteristics apply in general to the cultured bone marrow-derived MSCs (BMSCs), but some differences seem to be related to the tissue origin. As various phenotype and function studies revealed, MSCs isolated from different sources are not exactly equivalent and represent a highly heterogeneous populations of cells which are dramatically affected by various extrinsic and intrinsic factors. ${ }^{12}$ Therefore, safety, efficacy, reproducibility of MSCs production, and compliance with Good Manufacturing Practices criteria must be ensured. Hence, the most concerned questions refer to donor eligibility and screening, various types of isolation/enrichment protocols, open cultivation systems versus bioreactors, usage of different reagents, particularly media and supplements with/without animal or human origin, and controls ensuring safety and traceability of the final product. However, some other important issues such as adequate facility criteria, environmental controls, and cell storage concerns should also be addressed. ${ }^{13,14}$ Thus, in recent years, many efforts have been made to establish optimized protocols for Good Manufacturing Practices compliant preparation of MSCs, develop tools and define markers for their characterization, and describe and influence their differentiation and immunomodulatory potential in vitro and in vivo.

Typical feature of MSCs is their ability to differentiate into many cell types that are not only of mesenchymal origin. However, the process of differentiation requires action of specific growth factors and chemical mediators. ${ }^{8}$ Besides these, the process of differentiation is affected by many other factors such as density of cells and their arrangement, ${ }^{15-17}$ tissue origin from which MSCs are isolated, ${ }^{7}$ donor age, ${ }^{18}$ stage of the culture and passage, ${ }^{19-21}$ variety of electrical and mechanical forces involved, ${ }^{16,22-24}$ and physical properties of a substrate or carrier. ${ }^{24-26}$

One of the major characteristics of MSCs is that they have migratory abilities, ${ }^{27}$ that is, after administration, they specifically migrate to the sites of inflammation and tissue damage which is typically associated with cytokine outburst $^{28,29}$ (Figure 1).

MSCs secrete a wide variety of different growth factors, cytokines, and adhesion molecules by which they affect the microenvironment of the inflamed and degenerating target tissue and thus maintain positive paracrine effect on the tissue repair. ${ }^{30,31}$ Since MSCs exhibit significant immunomodulatory properties, they are able to escape the immune system recognition mechanisms and modulate the defense mechanisms of the host. Considering their low immunogenicity, MSCs are poorly recognized by human leukocyte antigen incompatible hosts. ${ }^{30,32}$ Therefore, they may well perform specific tasks such as immunomodulators in the maintenance of peripheral or transplantation tolerance, in autoimmune response, and tolerance between mother and fetus. ${ }^{8,33,34}$ The MSCs are able to influence many functions of activated $\mathrm{T}$ cells, ${ }^{35} \mathrm{~B}$ cells, ${ }^{36}$ and NK cells ${ }^{37}$ and can also affect the functions of dendritic cells (DCs), ${ }^{38,39}$ monocyte/macrophages, ${ }^{40,41}$ and neutrophils and mast cells ${ }^{42,43}$ (Figure 2). MSCs can mediate their immunomodulatory activity in a numerous models, such as graft versus host disease (GvHD), ${ }^{34,44}$ diabetes mellitus type $1,{ }^{45,46}$ experimental autoimmune encephalomyelitis (EAE) ${ }^{47}$ model of contusive spinal cord injury and its subsequent inflammation-related damage, ${ }^{48,49}$ and many others. ${ }^{33}$ They may also act as primary matrices in the tissue repair processes caused by the inflammation and injury. ${ }^{50,51}$ Because of high affinity to the tumor tissue, MSCs can also serve as the targeted carriers of therapeutic agents, as part of the tumor stroma in anticancer therapy. ${ }^{52,53}$

\section{Activities of MSCs in damaged tissue environment}

A key factor of multicellular organism survival is the maintenance of homeostatic balance. Under normal circumstances, apoptotic cells are removed, without causing inflammation, by resident phagocytic cells. On the other hand, acute tissue damage is usually accompanied with inflammation and cell 


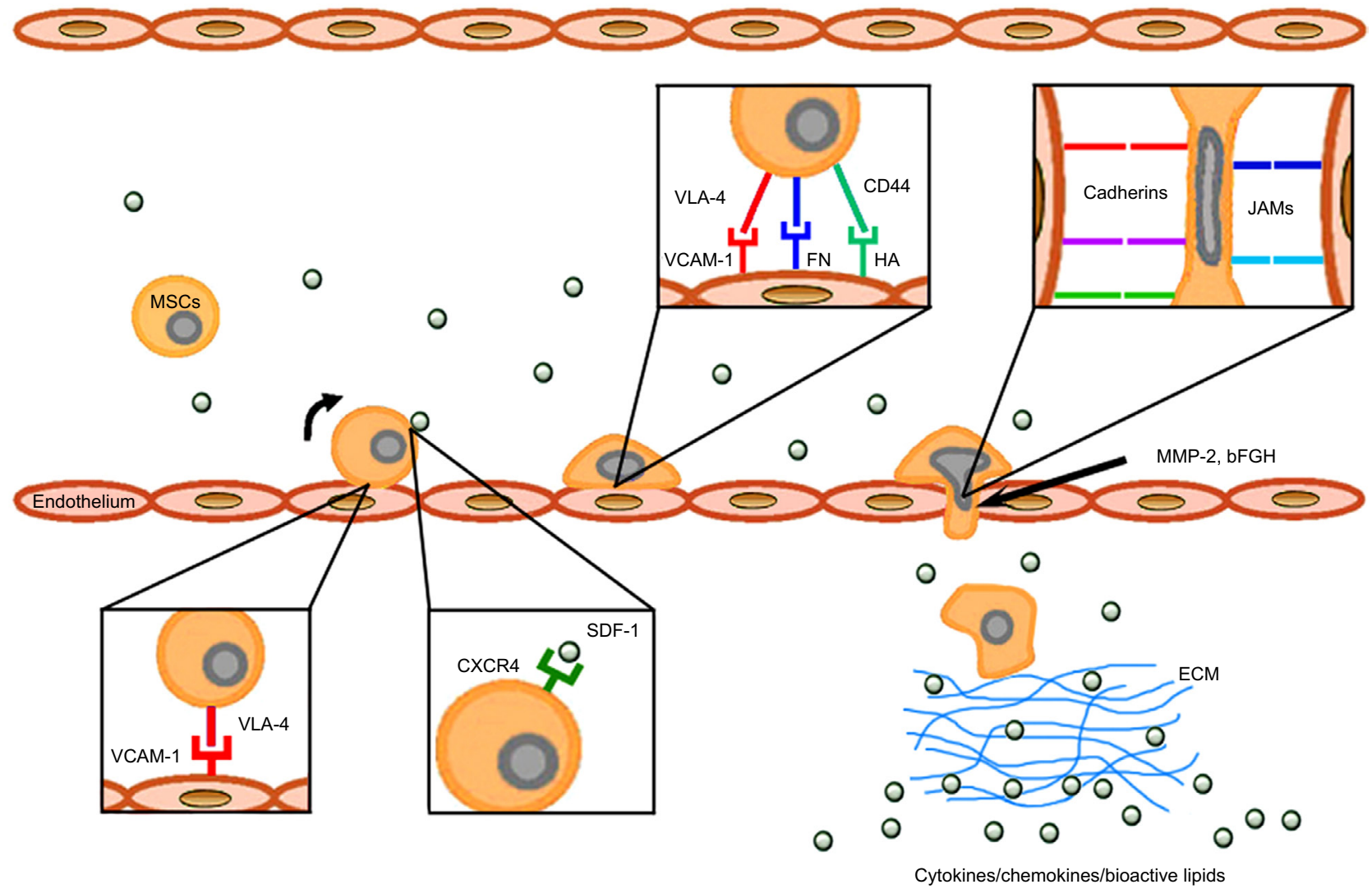

Figure I Mechanisms of MSC homing toward damaged tissue.

Abbreviations: MSC, mesenchymal stem cell; VLA-4, very late antigen-4; VCAM-I, vascular cell adhesion molecule I; FN, fibronectin; HA, hyaluronic acid; JAM, junction adhesion molecule; MMP-2, matrix metalloproteinase-2; bFGF, basic fibroblast growth factor; SDF-I, stromal cell-derived factor I; ECM, extracellular matrix.

components released from necrotic cells, and microvascular damage leads to the increased vasopermeability and subsequent infiltration of macrophages and neutrophils. ${ }^{54}$ The process of necrotic cell phagocytosis leads to the release of pro-inflammatory mediators, such as interferon- $\gamma$ (IFN- $\gamma)$, tumor necrosis factor- $\alpha$ (TNF- $\alpha$ ), interleukin-1 (IL-1), various chemokines, leukotrienes, and free radicals. ${ }^{55}$ Besides the innate immune response, damage and repair of tissues is closely associated with the action of the adaptive immune response involving CD4+ and CD8+ T cells and B cells. ${ }^{54}$

In recent years, MSCs have been recognized as one of the adult stem cell types, which actively participate in a tissue damage repair processes. ${ }^{50,51}$ In a case of tissue damage, the MSCs located in immediate vicinity or originated from bone marrow begin to migrate to the site of injury. ${ }^{28,29}$ Once the MSCs reach an injury site, they must cooperate closely with various types of stromal and inflammatory cells in order to participate in damage repair and regeneration processes. ${ }^{51,56}$ It has been shown that there are mutual interactions between the MSCs and inflammatory cells, which at the end determine the results of damaged tissue repair processes mediated by
MSCs. These undergoing mechanisms are very complex where modulatory factors produced by the MSCs play the major role (Figure 2). However, these mechanisms differ between various species. ${ }^{31,57}$ Many of these factors are released into exosomes, the small membranous vesicles participating in cell to cell communication. Regarding the repair and regeneration of damaged tissue, the exosomes from MSCs have similar functions as the MSCs, but little is known about the immunomodulatory effect of these vesicles. ${ }^{58}$

Several studies have demonstrated that MSCs are capable of producing a wide range of growth factors such as transforming growth factor- $\beta$ (TGF- $\beta$ ), hepatocyte growth factor (HGF), epidermal growth factor, fibroblast growth factor (FGF), vascular endothelial growth factor, platelet-derived growth factor (PDGF), insulin-like growth factor 1 (IGF-1), stromal cell-derived factor 1 (SDF-1), and angiopoietin-1..$^{30}$ Many of them are generated on the principle of nuclear factor- $\kappa \mathrm{B}(\mathrm{NF}-\mathrm{\kappa B})$ activation, after prior exposure to the pro-inflammatory stimuli such as IFN- $\gamma$, TNF- $\alpha$, IL-1 $\beta$, lipopolysaccharide (LPS), or hypoxia. ${ }^{59}$ These growth factors subsequently promote the development of tissue progenitor 


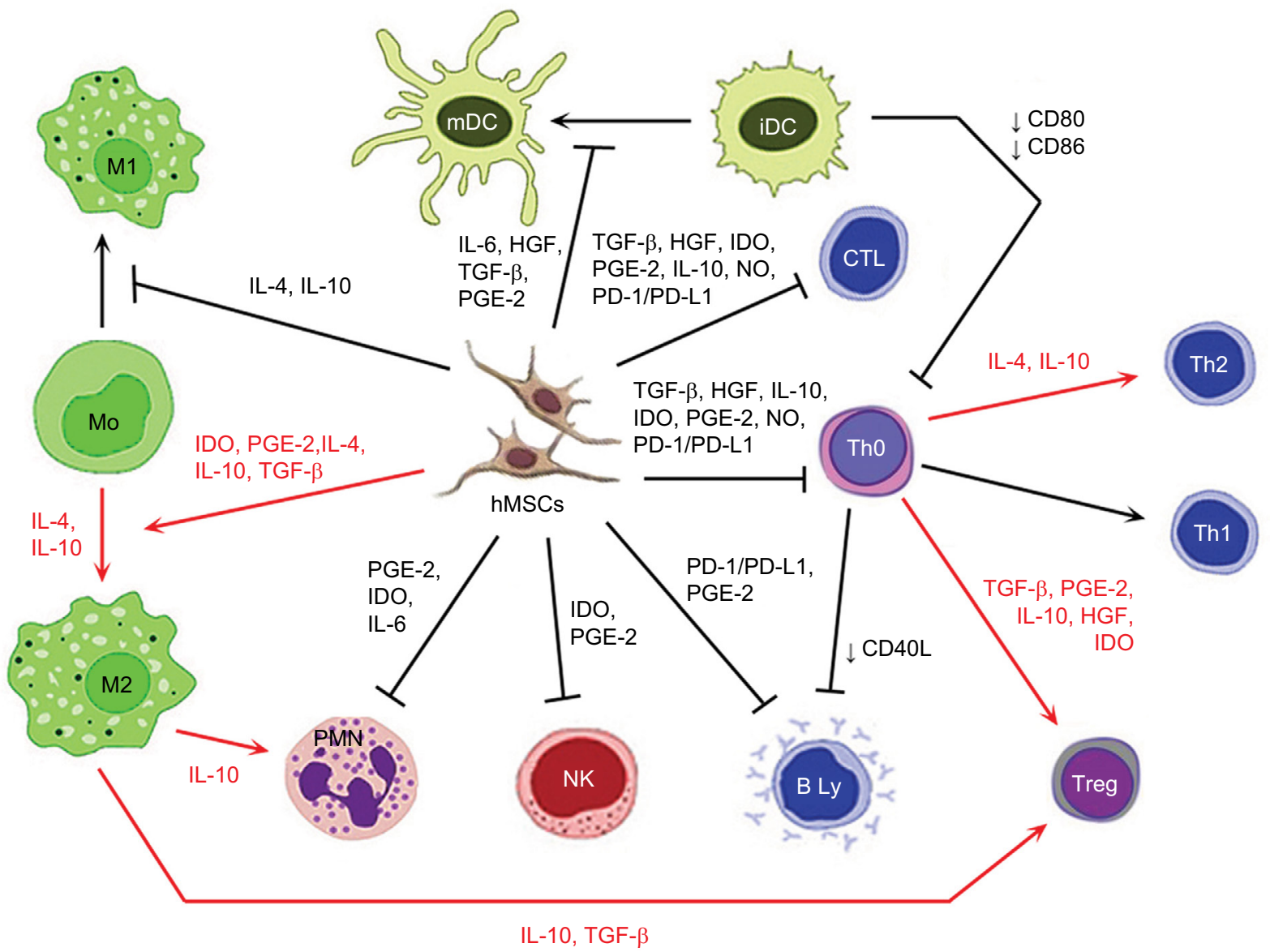

Figure 2 Immunomodulatory action of activated MSCs.

Notes: Red arrow: stimulation; black arrow: suppression; blunt-ended arrow: direct inhibition.

Abbreviations: iDC, immature dendritic cell; IL, interleukin; HGF, hepatocyte growth factor; TGF- $\beta$, transforming growth factor- $\beta$; PGE-2, prostaglandin E2; IDO, indoleamine 2,3-dioxygenase; NO, nitric oxide; PD-LI, programmed death ligand I; hMSC, human mesenchymal stem cell; Treg, T regulatory; Th, T helper; CTL, cytotoxic T cell; mDC, mature dendritic cell; PD-I, programmed cell death protein I; PMN, polymorphonuclear leukocyte; NK, NK cell.

cells, fibroblasts, and endothelial cells which then support tissue regeneration and repair. ${ }^{57}$

After an adequate pro-inflammatory stimulation, MSCs are also able to produce other important immunomodulatory factors such as prostaglandin E2 (PGE-2), indoleamine 2,3-dioxygenase (IDO), nitric oxide (NO), TNF-inducible gene 6 protein, TGF- $\beta$, and many others. ${ }^{30,31}$ There is also modification in the expressions of surface molecules, such as galectins, intracellular adhesion molecule 1 (ICAM-1), and vascular cell adhesion molecule 1 (VCAM-1). . $^{30,31}$

Within the course of action, MSCs are capable of in vitro and in vivo modulation of many types of immune cells. The ability to modulate the immune response is mediated by the action of complex mechanisms related mostly to the production of immunosuppressive trophic factors (Figure 2). The MSCs are able to inhibit the proliferation of $\mathrm{T}$ helper (Th) and cytotoxic $\mathrm{T}$ cells through multiple pathways. Moreover, induction of Th 2 and regulatory T cells (Treg) differentiation result in the induction of an anti-inflammatory environment. ${ }^{35}$ The maturation of immature dendritic cells (iDCs) is inhibited by IL-6, while reduction in the expression of co-stimulatory molecules CD40, CD80, and CD86 could cause an inhibition of $\mathrm{T}$ cell activation. ${ }^{35,39}$ Through the actions of MSCs, monocytes are directed to differentiate into alternative anti-inflammatory M2 phenotype. The most important mechanisms involved in this process are the effects induced by IDO, TGF- $\beta$, IL-10, and PGE- $2 .{ }^{41}$ IL-10 produced by $\mathrm{M} 2$ macrophages may subsequently increase the frequency of Treg cells associated with the decrease of tissue neutrophil migration. ${ }^{41}$ The MSCs are also able to inhibit the proliferation of $\mathrm{NK}$ cells as well as limit their cytotoxic activity and cytokine secretion. ${ }^{37}$ Correspondingly, the proliferation of $\mathrm{B}$ cells and antibody production are also negatively influenced. ${ }^{36}$

MSCs also have the ability to induce complement activation. It has been observed that high levels of activated C3 correlate with increased immunomodulatory capacity of the MSCs. ${ }^{60}$ In addition, MSCs express the complement 
regulating protein $\mathrm{CD} 59$ and complement factor $\mathrm{H}$ which protects cells from lysis. ${ }^{60,61}$

Therefore, MSCs have the potential to suppress uncontrolled immune responses, by in situ downregulation of the inflammatory response. Thus, it can be said that the immunomodulatory action of MSCs takes place in the microenvironment where inflammatory factors produced during the immune response directly affect the immunomodulatory capacity of MSCs. ${ }^{30,31,57}$

Additionally, aside the immunomodulatory actions, MSCs also contribute to reparation and regeneration of damaged tissue with their differentiation potential. As seen in the study by Spakova et al, focused on immunomodulatory and regenerative properties of MSCs in osteoarthritis model in vitro, kartogenin (KGN) may be an effective accelerant promoting chondrogenic differentiation of MSCs but with no significant effect on hypertrophic differentiation. KGN caused an upregulation of Col II and aggrecan expression and downregulation of osteocalcin and MMP-13 and caused an increase in the expressions of chondrogenic markers (CD49e, CD26, and CD54) compared to control. ${ }^{62}$

\section{Activation of immunomodulatory capacity of MSCs}

For the experimental and potential clinical applications, MSCs are typically used after various passages after in vitro expansion. Thus, their phenotype, differentiation, and immunomodulatory potential may significantly change during an in vitro expansion. ${ }^{19,20}$ Moreover, the therapeutic effects of the MSCs may differ due to the complexity and specific action of damaged tissue microenvironment.

Several results indicate that MSCs are not spontaneously immunosuppressive but that they require activation for the manifestation of their immunomodulatory properties. In particular, the most important priming factors of MSCs are IFN- $\gamma$, TNF- $\alpha$, and IL- $1 \beta .{ }^{63-65}$

One of the first modulatory factors that are produced after the $\mathrm{T}$ cell activation is IFN- $\gamma$. This cytokine would normally provide stimulatory signal for the activation and expansion of T cells, but in the presence of MSCs, it leads to the suppression of $\mathrm{T}$ cell proliferation and inhibition of biological functions. ${ }^{35}$ The release and binding of IFN- $\gamma$ on receptor expressed by the MSCs are key steps for the induction of the immunomodulatory properties not only for various $\mathrm{T}$ cell subtypes but also against B and NK cells, which are usually unresponsive to the IFN- $\gamma$ action in the absence of MSCs. ${ }^{35,36,39}$ Equally important factors that affect MSCs polarization are the concentration of IFN- $\gamma$ and contemporary release of inflammatory cytokines. It has been shown that MSCs modified by IFN- $\gamma$ can not only function as cells with immunomodulating properties but also act as effective antigen-presenting cells (APCs) ${ }^{66,67}$ However, the in vitro findings are difficult to associate with the in vivo microenvironment because of complexity and impossibility to measure IFN- $\gamma$ at the local level.

The next step involved in the activation of immunomodulatory activities of MSCs is the release of inflammatory cytokines such as TNF- $\alpha$ and IL-1 $\beta$ which alone are not able to inhibit $\mathrm{T}$ cell proliferation mediated by the MSCs. ${ }^{68}$ Synergic effect of IFN- $\gamma$ with one of the pro-inflammatory cytokines is then sufficient to activate the MSCs. This is associated with significant augmentation of the immunosuppressive effect. ${ }^{68}$ After either TNF- $\alpha$ or IL-1 $\beta$ action, there is a significant change in the MSCs phenotype. This includes an induction of MHC class I expression and increase of ICAM-1 and VCAM-1 expressions. ${ }^{69}$ There is also a de novo expression of MHC class II molecules that could theoretically support the APC function of MSCs. Additionally, the expression of programmed death ligand 1 (PD-L1) is detected. ${ }^{65,68,70}$ During the synergistic action of IFN- $\gamma$ and TNF- $\alpha$, stimulation of IL-8, IL-6, ${ }^{71} \mathrm{HGF}$, and PGE-2 expression and cyclooxygenase-2 (COX-2) activity can be observed. ${ }^{72}$ On the contrary, the use of IFN- $\gamma$ alone may result in the induction of IDO and PD-L1 expressions. ${ }^{65,72}$

The activation of human MSCs by pro-inflammatory stimuli, through the induction of COX-2 has a reducing impact on the heme oxygenase-1 (HO-1) activity. This action negatively influences the suppressor effects of MSCs, induction of Treg, and subsequent IL-10 production. ${ }^{64}$ Activation of MSCs through the interaction of IFN- $\gamma$ and TNF- $\alpha$ leads to the activation of superoxide dismutase 3 , which is an anti-inflammatory enzyme involved in the $\mathrm{O}_{2}{ }^{-}$catabolism. ${ }^{73}$ Moreover, the coactivation of MSCs by IFN- $\gamma$ and TNF- $\alpha$ induces the production of chemokines, such as CCR5, CCR10, CXCR3, CXCL9, and CXCL10, which are involved in chemotaxis and can inhibit proliferation of the immune system effector cells. ${ }^{68,71}$ These processes are essential for the inhibition of $\mathrm{T}$ cell function in vitro as well as for the prevention of delayed type hypersensitivity and GvHD in vivo. ${ }^{34,44}$ Through the complex interactions between the pro-inflammatory factors, the production and activity of various immunomodulatory molecules produced by MSCs are established. ${ }^{30,31}$

Besides these pro-inflammatory cytokines, in relation to the activation of MSCs, signaling through the Toll-like receptors (TLRs) was also previously described. ${ }^{74}$ The 
MSCs priming through the TLR3 and TLR4 resulted in an intensification of their in vitro immunomodulation capacity. The MSCs were thus able to function through the expression of IDO induced through protein kinase R and IFN- $\beta$ signaling. ${ }^{75}$ However, the opposite effect was also observed. Binding of TLR3 and TLR4 ligands has reduced the expression of Jagged-1 which leads to the failure of MSCs' ability to modulate $\mathrm{T}$ cell responses on cell contact-dependent manner. ${ }^{76}$ Explanation of these different outcomes may be based on the findings that TLR3 and TLR4 activate MSCs in different ways. Activation through TLR4 with LPS induced the pro-inflammatory phenotype of MSCs where secretion of IL-6, IL-8, and TGF- $\beta$ was intensified by co-stimulation with IFN $-\gamma \cdot{ }^{77-79}$ On the other hand, activation through TLR3 with polyinosinic:polycytidylic acid (poly I:C) induced anti-inflammatory phenotype of MSCs where production of IDO, PGE-2, IL-4, and IL-1RA was detected. ${ }^{77,79}$ Similarly, in a recent work, there were observed important changes in the expression of immunomodulatory factors and adhesion molecules of chorion derived MSCs activated through TLR3-poly I:C interaction, after further cocultivation with activated lymphocytes. In particular, a great increase in IL-10 expression and positive changes in CD44 and ICAM-1 expression were also observed (Bačenková, unpublished data, 2016). These findings suggest that MSCs are susceptible to various environmental stimuli which significantly affect the activation of MSCs and their subsequent immunomodulatory functions..$^{63,74}$

\section{Migration of MSCs to the site of injury}

Migration process is represented by several distinctive steps and starts with the resistance and adhesive interactions between cells flowing through the bloodstream and vascular endothelium. The first step is mediated by the homing receptors expressed on circulating cells which interact with the corresponding co-receptors presented on endothelium. Their interaction leads to the connection of circulating cells to the endothelium and induces rolling effect on the cell surface. This step is usually associated with chemokine-induced activation of integrins, tight adhesion of circulating cells to endothelium, and subsequent extravasation. ${ }^{28,29}$

For the successful targeted cell therapy, it is critically important to control cell adhesion to the target tissue extracellular matrix (ECM) through the expression of specific adhesion molecules. ${ }^{28,29,69}$ The MSCs express a large number of adhesion molecules which include integrins and selectins. Heterodimeric protein $\alpha 4 / \beta 1$ integrin, also known as a very late antigen-4 (VLA-4), is a member of integrin family and a cell surface adhesion molecule that mediates the cell-matrix or cell-cell interactions. These interactions are provided through binding to the VCAM-1 and V-region of fibronectin. ${ }^{80}$ The MSCs also express CD44 molecule which is a receptor for the hyaluronic acid and can interact with other ligands such as osteopontin, collagens, and matrix metalloproteinases (MMPs). ${ }^{29,81}$

It has been shown that $\alpha 4 / \beta 1$ is one of integrins that can mediate initial interaction, rolling, and firm adhesion during the process of MSCs homing ${ }^{28,29}$ (Figure 1). The MSCs interact with endothelial cells in a coordinated manner through the $\alpha 4 / \beta 1$ integrin-VCAM- 1 interaction, $\beta 1$ integrin, P-selectin, MMP-2, and a cytokines secretion. ${ }^{82}$ It has also been shown that VCAM-1 promotes adhesion of many other cells types and is the primary endothelial ligand for $\alpha 4 / \beta 1, \beta 1$, and $\alpha 4 / \beta 7$ integrin. ${ }^{83}$ Its over-expression occurs in endothelial cells as a response to the action of the TNF- $\alpha$ and IL-1 $\beta$ cytokines. ${ }^{69,84}$

Another factor involved in the homing process is fibronectin (FN), which binds to the ECM components such as collagen, fibrin, and heparan sulfate. These interactions play a fundamental role within the processes of cell adhesion, growth, migration, differentiation, and wound healing. ${ }^{85}$ The FN fragmentation initiates additional exposure of the V-region containing a binding site for the $\alpha 4 / \beta 1$ integrin expressed on the MSCs. These FN fragments cause an increase in bonding strength of the $\alpha 4 / \beta 1$ integrin-expressing cells, thus allowing them to adhere to the surrounding matrix. ${ }^{80,85}$ Interaction between $\alpha 4 / \beta 1$ integrin and FN plays an important role in the process of transmigration of MSCs into the ECM. Final step in the process of transmigration of MSCs into ECM is also facilitated through the interactions of MSCs with integrins, junction adhesion molecules (JAMs), and cadherins ${ }^{86}$ (Figure 1).

It was found that the migration ability of MSCs is under the strict control of a wide range of growth factors such as PDGF or IGF-1 operating under the receptor tyrosine kinase principle. However, the findings of the present study suggest that only a limited number of BMSCs used in systemic transplantations possess homing capacity toward injured tissue. A molecular signature that defines this population has been identified, and a surface marker PDGFR $\beta$ can be employed for potential isolation of the BMSCs with enhanced migratory capacity. ${ }^{87}$ Recent data also demonstrate functional association between in vivo bone forming ability and homing capacity of BMSCs. Therefore, PDGFR $\beta$ can be used as a potential marker for future selection of BMSCs populations with high migration and bone formation capacity. ${ }^{87}$ 
Various chemokines such as CCR2, CCR3, CCR4, and CCL5 are also involved in the homing process. ${ }^{28,29,88}$ However, the resulting effect of most chemokines is more intensive after the stimulation with TNF- $\alpha$ and IL- $1 \beta{ }^{89}$ Findings suggest that the mobilization and subsequent migration of MSCs to the site of injury depend on the state of local and systemic inflammatory microenvironment ${ }^{28,29,89}$ (Figure 1).

Migration process is from a large part dependent on the chemokine attraction. A key molecule in this step is SDF-1, also known as CXC chemokine ligand 12 (CXCL12). It is a small chemotactic cytokine that is often induced by pro-inflammatory stimuli such as TNF- $\alpha$ and IL-1. ${ }^{28,29}$ The receptor for this chemokine is CXCR4, and the SDF-1CXCR4 interaction is rather exclusive and plays an important role in the migration process of $\mathrm{MSCs}^{29,81}$ (Figure 1). Since the SDF-1 is constitutively expressed on various cells and tissues, it was suggested that this molecule may play a preferable role in immune surveillance and basal extravasation. ${ }^{90}$

It is also well known that culture conditions significantly influence the functions of MSCs. Since exogenously administrated MSCs always have to be expanded in vitro, it has been observed that MSCs can acquire or lose certain surface receptors during the cultivation which might subsequently affect their homing ability. ${ }^{27,91,92}$ In particular, CXCR4 is expressed at high levels in the bone marrow and ischemic tissues but disappears from the MSCs surface after cultivation. However, hypoxic culture condition can enhance the expressions of CXCR4 and CX3CR1, and the addition of cytokines to the MSCs culture can also restore the CXCR4 levels. ${ }^{93}$

Basic fibroblast growth factor (bFGF) and MMPs are other factors that can modulate MSCs homing (Figure 1). bFGF can increase the migration activity of MSCs through the activation of Akt signaling pathway. However, depending on the bFGF concentration, its function can also have the opposite effect on MSCs homing. It has been shown that low concentrations of bFGF result in the attraction of cells, whereas higher concentration has the opposite effect. This ambivalent action of bFGF provides another opportunity for targeting the MSCs homing. ${ }^{94}$ MMP-2 is another active molecule expressed by MSCs, involved in the degradation of collagen IV, a major component of basement membrane. It was shown that MMP-2 expressed by MSCs is functionally involved in the process of transmigration across the endothelium. ${ }^{86,95}$

\section{Conclusion}

In the last few years, there have been significant advances in the process of understanding the complex steps involved in the MSCs-mediated modulation of immune responses. The final fate of MSCs in local microenvironment and the precise mechanisms through which these cells act in a paracrine manner against neighboring somatic and progenitor cells are yet to be elucidated in detail. Some of the significant immunomodulatory effects are based on distinct properties of MSCs. However, to carry out the modulatory functions, MSCs have to be primed by pro-inflammatory cytokines. Initial data support the paradigm that MSCs are susceptible to the action of the microenvironment. This study proposes that both the concentration and duration of the stimulus have an important role in the process of polarization of MSCs. Therefore, the final modulatory activity of MSCs depends on the action of various factors associated with the contradictory effects. However, in general, these interactions ultimately result in functional polarization of the MSCs toward inhibitory and less to the pro-inflammatory phenotype. It also seems that even long-term implantation, or in some cases even the mere location of MSCs within lesion, is not necessary for MSCs to exert their immunomodulatory and pro-reparatory ability. The MSCs have the potential to modulate and reprogram the functions of the immune system cell and thus support the host immune defense or inhibit the inflammatory processes. Additionally, due to low immunogenicity and ability to migrate to the sites of tissue injury associated with cytokine outburst, MSCs may serve as carriers for the therapeutic agents. As a component of the stroma in some tumors, MSCs can be possibly used in anticancer therapy. However, it is necessary to investigate further not only the final mechanisms of action but also the series of events occurring at different steps of immunomodulation. It is also necessary to address the questions how to manipulate and influence MSCs to achieve the desired degree of differentiation and how to modulate their homing abilities.

\section{Acknowledgments}

This work was supported by the Slovak Research and Development Agency under the contract No. APVV-0684-12, by the grant of the Operational Program Research and Development, cofinanced by the European Regional Development Fund OPVaV-2012/2.2/08-RO - Medical University Science Park in Košice (MEDIPARK, Košice; ITMS: 26220220185), and by the grant VEGA No. 1/0217/16.

\section{Author contributions}

All the authors participated in the design of the article, interpretation of the studies, and critical revision of the manuscript. 


\section{Disclosure}

The authors report no conflicts of interest in this work.

\section{References}

1. Friedenstein AJ, Petrakova KV, Kurolesova AI, Frolova GP. Heterotopic of bone marrow. Analysis of precursor cells for osteogenic and hematopoietic tissues. Transplantation. 1968;6:230-247.

2. Corselli M, Chen CW, Crisan M, Lazzari L, Péault B. Perivascular ancestors of adult multipotent stem cells. Arterioscler Thromb Vasc Biol. 2010;30(6):1104-1109.

3. Hoshino A, Chiba H, Nagai K, Ishii G, Ochiai A. Human vascular adventitial fibroblasts contain mesenchymal stem/progenitor cells. Biochem Biophys Res Commun. 2008;368:305-310.

4. Bačenková D, Rosocha J, Tóthová T, Rosocha L, Šarisský M. Isolation and basic characterization of human term amnion and chorion mesenchymal stromal cells. Cytotherapy. 2011;13(9):1047-1056.

5. Bunnell BA, Flaat M, Gagliardi C, Patel B, Ripoll C. Adiposederived stem cells: Isolation, expansion and differentiation. Methods. 2008;45:115-120.

6. Harvanová D, Tóthová T, Sarišský M, Amrichová J, Rosocha J. Isolation and characterization of synovial mesenchymal stem cells. Folia Biol (Praha). 2011;57(3):119-124.

7. Hass R, Kasper C, Böhm S, Jacobs R. Different populations and sources of human mesenchymal stem cells (MSC): A comparison of adult and neonatal tissue-derived MSC. Cell Commun Signal. 2011;9:12.

8. Hwang NS, Zhang C, Hwang YS, Varghese S. Mesenchymal stem cell differentiation and roles in regenerative medicine. Wiley Interdiscip Rev Syst Biol Med. 2009;1(1):97-106.

9. Friedenstein AJ, Chailakhjan RK, Lalykina KS. The development of fibroblast colonies in monolayer cultures of guinea-pig bone marrow and spleen cells. Cell Tissue Kinet. 1970;3:393-403.

10. Donnenberg AD, Meyer EM, Rubin JP, Donnenberg VS. The cellsurface proteome of cultured adipose stromal cells. Cytometry A. 2015;87(7):665-674.

11. Dominici M, Le Blanc K, Mueller I, et al. Minimal criteria for defining multipotent mesenchymal stromal cells. The International Society for Cellular Therapy position statement. Cytotherapy. 2006;8:315-317.

12. Phinney DG, Sensebé L. Mesenchymal stromal cells: misconceptions and evolving concepts. Cytotherapy. 2013;15:140-145.

13. Pacini S. Deterministic and stochastic approaches in the clinical application of mesenchymal stromal cells (MSCs). Front Cell Dev Biol. 2014;2:50.

14. Sensebé L, Gadelorge M, Fleury-Cappellesso S. Production of mesenchymal stromal/stem cells according to good manufacturing practices: a review. Stem Cell Res Ther. 2013;4(3):66.

15. Discher DE, Mooney DJ, Zandstra PW. Growth factors, matrices, and forces combine and control stem cells. Science. 2009;324(5935): 1673-1677.

16. Wang YK, Chen CS. Cell adhesion and mechanical stimulation in the regulation of mesenchymal stem cell differentiation. J Cell Mol Med. 2013;17(7):823-832.

17. Zippel N, Limbach CA, Ratajski N, et al. Purinergic receptors influence the differentiation of human mesenchymal stem cells. Stem Cells Dev. 2012;21(6):884-900.

18. Choudhery MS, Badowski M, Muise A, Pierce J, Harris DT. Donor age negatively impacts adipose tissue-derived mesenchymal stem cell expansion and differentiation. J Transl Med. 2014;12(1):8.

19. Binato R, de Souza Fernandez T, Lazzarotto-Silva C, et al. Stability of human mesenchymal stem cells during in vitro culture: considerations for cell therapy. Cell Prolif. 2013;46(1):10-22.

20. Madeira A, da Silva CL, dos Santos F, Camafeita E, Cabral JM., SáCorreia I. Human mesenchymal stem cell expression program upon extended ex-vivo cultivation, as revealed by 2-DE-based quantitative proteomics. PLoS One. 2012;7(8):e43523.
21. Wagner W, Horn P, Castoldi M, et al. Replicative senescence of mesenchymal stem cells: a continuous and organized process. PLoS One. 2008;3:e2213.

22. Jansen JH, van der Jagt OP, Punt BJ, Verhaar JA, van Leeuwen JP, Weinans H, Jahr H. Stimulation of osteogenic differentiation in human osteoprogenitor cells by pulsed electromagnetic fields: an in vitro study. BMC Musculoskelet Disord. 2010;11:188-199.

23. Hess R, Douglas T, Myers KA, et al. Hydrostatic pressure stimulation of human mesenchymal stem cells seeded on collagen-based artificial extracellular matrices. J Biomech Eng. 2010;132(2):1-6.

24. Tsimbouri PM. Adult stem cell responses to nanostimuli. J Funct Biomater. 2015;6(3):598-622.

25. Engler AJ, Sen S, Sweeney HL, Discher DE. Matrix elasticity directs stem cell lineage specification. Cell. 2006;126:677-689.

26. Guilak F, Cohen DM, Estes BT, Gimble JM, Liedtke W, Chen CS. Control of stem cell fate by physical interactions with the extracellular matrix. Cell Stem Cell. 2009;5(1):17-26.

27. Nagyova M, Slovinska L, Blasko J, et al. A comparative study of PKH67, DiI, and BrdU labeling techniques for tracing rat mesenchymal stem cells. In Vitro Cell Dev Biol Anim. 2014;50(7):656-663.

28. Eggenhofer E, Luk F, Dahlke MH, Hoogduijn MJ. The life and fate of mesenchymal stem cells. Front Immunol. 2014;5:148.

29. Sohni A, Verfaillie CM. Mesenchymal stem cells migration homing and tracking. Stem Cells Int. 2013;2013:130763.

30. English K. Mechanisms of mesenchymal stromal cell immunomodulation. Immunol Cell Biol. 2013;91:19-26.

31. Zachar L, Bačenková D, Soltys J, Rosocha J. Bioactive mediators associated with mesenchymal stem cells-mediated immunomodulation. $J J$ Bone Stem Res. 2015;1(2):006.

32. Shi Y, Su J, Roberts AI, Shou P, Rabson AB, Ren G. How mesenchymal stem cells interact with tissue immune responses. Trends Immunol. 2012;33(3):136-143.

33. Farini A, Sitzia C, Erratico S, Meregalli M, Torrente Y. Clinical applications of mesenchymal stem cells in chronic diseases. Stem Cells Int. 2014;2014:306573.

34. Yin F, Battiwalla M, Ito S, et al. Bone marrow mesenchymal stromal cells to treat tissue damage in allogeneic stem cell transplant recipients: correlation of biological markers with clinical responses. Stem Cells. 2014;32(5):1278-1288.

35. Duffy MM, Ritter T, Ceredig R, Griffin MD. Mesenchymal stem cell effects on T-cell effector pathways. Stem Cell Res Ther. 2011;2(4):34.

36. Franquesa M, Hoogduijn MJ, Bestard O, Grinyó JM. Immunomodulatory effect of mesenchymal stem cells on B cells. Front Immunol. 2012;3:212.

37. Casado JG, Tarazona R, Sanchez-Margallo FM. NK and MSCs crosstalk: the sense of immunomodulation and their sensitivity. Stem Cell Rev. 2013;9(2):184-189.

38. Spaggiari GM, Abdelrazik H, Becchetti F, Moretta L. MSCs inhibit monocyte-derived DC maturation and function by selectively interfering with the generation of immature DCs: central role of MSC-derived prostaglandin E2. Blood. 2009;113(26):6576-6583.

39. Spaggiari GM, Moretta L. Interactions between mesenchymal stem cells and dendritic cells. Adv Biochem Eng Biotechnol. 2013;130:199-208.

40. Cutler AJ, Limbani V, Girdlestone J, Navarrete CV. Umbilical cordderived mesenchymal stromal cells modulate monocyte function to suppress T cell proliferation. J Immunol. 2010;185:6617-6623.

41. François M, Romieu-Mourez R, Li M, Galipeau J. Human MSC suppression correlates with cytokine induction of indoleamine 2,3-dioxygenase and bystander M2 macrophage differentiation. Mol Ther. 2012;20:187-195.

42. Brown JM, Németh K, Kushnir-Sukhov NM, Metcalfe DD, Mezey E. Bone marrow stromal cells inhibit mast cell function via a COX2dependent mechanism. Clin Exp Allergy. 2011;41:526-534.

43. Lombardo E, van der Poll T, DelaRosa O, Dalemans W. Mesenchymal stem cells as a therapeutic tool to treat sepsis. World J Stem Cells. 2015;7(2):368-379. 
44. Newell LF, Deans RJ, Maziarz RT. Adult adherent stromal cells in the management of graft-versus-host disease. Expert Opin Biol Ther. 2014;14(2):231-246.

45. Katuchova J, Tothova T, Farkasova Iannaccone $\mathrm{S}$, et al. Impact of different pancreatic microenvironments on improvement in hyperglycemia and insulin deficiency in diabetic rats after transplantation of allogeneic mesenchymal stromal cells. J Surg Res. 2012;178(1):188-195.

46. Katuchova J, Harvanova D, Spakova T, et al. Mesenchymal stem cells in the treatment of type 1 diabetes mellitus. Endocr Pathol. 2015;26(2):95-103.

47. Glenn JD, Smith MD, Calabresi PA, Whartenby KA. Mesenchymal stem cells differentially modulate effector $\mathrm{CD} 8+\mathrm{T}$ cell subsets and exacerbate experimental autoimmune encephalomyelitis. Stem Cells. 2014, 32(10):2744-2755.

48. Cizkova D, Novotna I, Slovinska L, Vanicky I, Jergova S, Rosocha J, Radonak J. Repetitive intrathecal catheter delivery of bone marrow mesenchymal stromal cells improves functional recovery in a rat model of contusive spinal cord injury. J Neurotrauma. 2011;28(9):1951-1961.

49. Cizkova D, Devaux S, Le Marrec-Croq F, et al. Modulation properties of factors released by bone marrow stromal cells on activated microglia: an in vitro study. Sci Rep. 2014;4:7514.

50. Han Z, Jing Y, Zhang S, Liu Y, Shi Y, Wei L. The role of immunosuppression of mesenchymal stem cells in tissue repair and tumor growth Cell Biosci. 2012;2(1):8.

51. Kalinina NI, Sysoeva VY, Rubina KA, Parfenova YV, Tkachuk VA Mesenchymal stem cells in tissue growth and repair. Acta Naturae. 2011;3(4):30-37.

52. Barcellos-de-Souza P, Gori V, Bambi F, Chiarugi P. Tumor microenvironment: Bone marrow-mesenchymal stem cells as key players. Biochim Biophys Acta. 2013;1836(2):321-335.

53. Gjorgieva D, Zaidman N, Bosnakovski D. Mesenchymal stem cells for anti-cancer drug delivery. Recent Pat Anticancer Drug Discov. 2013;8(3):310-318.

54. Medzhitov R. Inflammation 2010: new adventures of an old flame. Cell. 2010;140:771-776.

55. Krysko DV, Denecker G, Festjens N, Gabriels S, Parthoens E, D‘Herde K, Vandenabeele P. Macrophages use different internalization mechanisms to clear apoptotic and necrotic cells. Cell Death Differ. 2006;13:2011-2022

56. Chen Y, Xiang LX, Shao JZ, Pan RL, Wang YX, Dong XJ, Zhang GR Recruitment of endogenous bone marrow mesenchymal stem cells towards injured liver. J Cell Mol Med. 2010;14:1494-1508.

57. Ma S, Xie N, Li W, Yuan B, Shi Y, Wang Y. Immunobiology of mesenchymal stem cells. Cell Death Differ. 2014;21(2):216-225.

58. Blazquez R, Sanchez-Margallo FM, de la Rosa O, Dalemans W, Alvarez V, Tarazona R, Casado JG. Immunomodulatory potential of human adipose mesenchymal stem cells derived exosomes on in vitro stimulated T cells. Front Immunol. 2014;5:556.

59. Crisostomo PR, Wang Y, Markel TA, Wang M, Lahm T, Meldrum DR. Human mesenchymal stem cells stimulated by TNF-alpha, LPS, or hypoxia produce growth factors by an NF kappa B- but not JNK-dependent mechanism. Am J Physiol Cell Physiol. 2008;294:C675-C682.

60. Moll G, Jitschin R, von Bahr L, et al. Mesenchymal stromal cells engage complement and complement receptor bearing innate effector cells to modulate immune responses. PLoS One. 2011;6:e21703.

61. Tu Z, Li Q, Bu H, Lin F. Mesenchymal stem cells inhibit complement activation by secreting factor H. Stem Cells Dev. 2010;19(11):1803-1809.

62. Spakova T, Plsikova J, Harvanova D, Lacko M, Rosocha J. Effect of in vitro differentiation of human mesenchymal stem cells on cartilage repair in osteoarthritis of knee joint. Eur Cell Mater. 2016;32(Suppl 3):61.

63. Krampera M. Mesenchymal stromal cell 'licensing': a multistep process. Leukemia. 2011;25:1408-1414.

64. Mougiakakos D, Jitschin R, Johansson CC, Okita R, Kiessling R, Le Blanc $\mathrm{K}$. The impact of inflammatory licensing on heme oxygenase-1mediated induction of regulatory $\mathrm{T}$ cells by human mesenchymal stem cells. Blood. 2011;117:4826-4835.
65. Sheng $\mathrm{H}$, Wang $\mathrm{Y}$, Jin $\mathrm{Y}$, et al. A critical role of IFNgamma in priming MSC-mediated suppression of T cell proliferation through up-regulation of B7-H1. Cell Res. 2008;18:846-857.

66. Chan JL, Tang KC, Patel AP, Bonilla LM, Pierobon N, Ponzio NM, Rameshwar P. Antigen-presenting property of mesenchymal stem cells occurs during a narrow window at low levels of interferon-gamma. Blood. 2006;107:4817-4824.

67. Sánchez-Abarca LI,Alvarez-Laderas I, Díez Campelo M, et al. Uptake and delivery of antigens by mesenchymal stromal cells. Cytotherapy. 2013; 15(6):673-678.

68. Ren G, Zhang L, Zhao X, et al. Mesenchymal stem cell-mediated immunosuppression occurs via concerted action of chemokines and nitric oxide. Cell Stem Cell. 2008;2:141-150.

69. Ren G, Zhao X, Zhang L, et al. Inflammatory cytokine-induced intercellular adhesion molecule-1 and vascular cell adhesion molecule-1 in mesenchymal stem cells are critical for immunosuppression. J Immunol. 2010; 184:2321-2328

70. Rameshwar P. IFN-gamma and B7-H1 in the immunology of mesenchymal stem cells. Cell Res. 2008;18:846-857.

71. Hemeda H, Jakob M, Ludwig AK, Giebel B, Lang S, Brandau S. IFN-gamma and TNF-alpha differentially affect cytokine expression and migration properties of mesenchymal stem cells. Stem Cells Dev. 2010;19:693-706.

72. English K, Barry FP, Field-Corbett CP, Mahon BP. IFN-gamma and TNF-alpha differentially regulate immunomodulation by murine mesenchymal stem cells. Immunol Lett. 2007;110:91-100.

73. Kemp K, Gray E, Mallam E, Scolding N, Wilkins A. Inflammatory cytokine induced regulation of superoxide dismutase 3 expression by human mesenchymal stem cells. Stem Cell Rev. 2010;6:548-559.

74. DelaRosa O, Dalemans W, Lombardo E. Toll-like receptors as modulators of mesenchymal stem cells. Front Immun. 2012;3:182.

75. Opitz CA, Litzenburger UM, Lutz C, et al. Toll-like receptor engagement enhances the immunosuppressive properties of human bone marrow-derived mesenchymal stem cells by inducing indoleamine2,3-dioxygenase-1 via interferon-beta and protein kinase R. Stem Cells. 2009;27:909-919.

76. Liotta F, Angeli R, Cosmi L, et al. Toll-like receptors 3 and 4 are expressed by human bone marrow-derived mesenchymal stem cells and can inhibit their T-cell modulatory activity by impairing Notch signaling. Stem Cells. 2008;26:279-289.

77. Hwang SH, Cho HK, Park SH, et al. Toll like receptor $3 \& 4$ responses of human turbinate derived mesenchymal stem cells: stimulation by double stranded RNA and lipopolysaccharide. PLoS One. 2014;9(7):e101558.

78. Romieu-Mourèz R, François M, Boivin MN, Bouchentouf M, Spaner DE, Galipeau J. Cytokine modulation of TLR expression and activation in mesenchymal stromal cells leads to a proinflammatory phenotype. J Immunol. 2009;182:7963-7973.

79. Waterman RS, Tomchuck SL, Henkle SL, Betancourt AM. A new mesenchymal stem cell (MSC) paradigm: polarization into a proinflammatory $\mathrm{MSC} 1$ or an immunosuppressive $\mathrm{MSC} 2$ phenotype. PLoS One. 2010;5:e10088.

80. Guan JL, Hynes RO. Lymphoid cells recognize an alternatively spliced segment of fibronectin via the integrin receptor alpha 4 beta 1 . Cell. 1990;60(1):53-61.

81. Marquez-Curtis LA, Janowska-Wieczorek A. Enhancing the migration ability of mesenchymal stromal cells by targeting the SDF-1/CXCR4 axis. Biomed Res Int. 2013;2013:561098.

82. Ruster B, Gottig S, Ludwig RJ, Bistrian R, Muller S, Seifried E, et al. Mesenchymal stem cells display coordinated rolling and adhesion behavior on endothelial cells. Blood. 2006;108(12):3938-3944.

83. Springer TA. Adhesion receptors of the immune system. Nature. 1990;346(6283):425-434.

84. Wu TC. The role of vascular cell adhesion molecule-1 in tumor immune evasion. Cancer Res. 2007;67(13):6003-6006.

85. Valenick LV, Hsia HC, Schwarzbauer JE. Fibronectin fragmentation promotes alpha4beta1 integrin-mediated contraction of a fibrin-fibronectin provisional matrix. Exp Cell Res. 2005;309(1):48-55. 
86. Steingen C, Brenig F, Baumgartner L, Schmidt J, Schmidt A, Bloch W. Characterization of key mechanisms in transmigration and invasion of mesenchymal stem cells. J Mol Cell Cardiol. 2008;44(6):1072-1084.

87. Andersen RK, Zaher W, Larsen KH, et al. Association between in vivo bone formation and ex vivo migratory capacity of human bone marrow stromal cells. Stem Cell Res Ther. 2015;6:196.

88. Honczarenko M, Le Y, Swierkowski M, Ghiran I, Glodek AM, Silberstein LE. Human bone marrow stromal cells express a distinct set of biologically functional chemokine receptors. Stem Cells. 2006;24(4): 1030-1041.

89. Ponte AL, Marais E, Gallay N, et al. The in vitro migration capacity of human bone marrow mesenchymal stem cells: comparison of chemokine and growth factor chemotactic activities. Stem Cells. 2007;25(7):1737-1745.

90. Bleul CC, Fuhlbrigge RC, Casasnovas JM, Aiuti A, Springer TA. A highly efficacious lymphocyte chemoattractant, stromal cell-derived factor 1 (SDF-1). J Exp Med. 1996;184(3):1101-1109.
91. Karp JM, Leng Teo GS. Mesenchymal stem cell homing: the devil is in the details. Cell Stem Cell. 2009;4:206-216.

92. Rombouts WJ, Ploemacher RE. Primary murine MSC show highly efficient homing to the bone marrow but lose homing ability following culture. Leukemia. 2003;17:160-170.

93. Hung SC, Pochampally RR, Hsu SC, Sanchez C, Chen SC, Spees J, Prockop DJ. Short-term exposure of multipotent stromal cells to low oxygen increases their expression of CX3CR 1 and CXCR4 and their engraftment in vivo. PLoS One. 2007;2:e416.

94. Schmidt A, Ladage D, Schinkothe T, et al. Basic fibroblast growth factor controls migration in human mesenchymal stem cells. Stem Cells. 2006;24(7):1750-1758.

95. De Becker A, Van Hummelen P, Bakkus M, Van de Broek I, De Wever J, De Waele M, Van Riet I. Migration of culture-expanded human mesenchymal stem cells through bone marrow endothelium is regulated by matrix metalloproteinase-2 and tissue inhibitor of metalloproteinase-3. Haematologica. 2007;92(4):440-449.
Journal of Inflammation Research

\section{Publish your work in this journal}

The Journal of Inflammation Research is an international, peer-reviewed open access journal that welcomes laboratory and clinical findings on the molecular basis, cell biology and pharmacology of inflammation including original research, reviews, symposium reports, hypothesis formation and commentaries on: acute/chronic inflammation; mediators of
Dovepress

inflammation; cellular processes; molecular mechanisms; pharmacology and novel anti-inflammatory drugs; clinical conditions involving inflammation. The manuscript management system is completely online and includes a very quick and fair peer-review system. Visit http://www.dove press.com/testimonials.php to read real quotes from published authors. 